\title{
PARA PENSAR O APAGAMENTO RITUALIZADO DOS CORPOS NA CRECHE: ADULTOS, BEBÊS, ATIVIDADES
}

\author{
Patrícia Vieira Bonfim ${ }^{\mathrm{i}}$ \\ Luciana Esmeralda Ostetto ${ }^{\text {ii }}$
}

\begin{abstract}
Resumo: Este texto focaliza narrativas corporais de professoras e bebês nos espaços e tempos de uma creche pública. No que se refere à metodologia, os dados foram gerados por meio de registros escritos e fotográficos visando capturar cenas de professoras e bebês em interação. Em um segundo momento foram realizados encontros com as docentes para conversas e análises sobre as cenas visíveis nos registros fotográficos suscitando narrativas outras. Os resultados revelaram que, em rotinas automatizadas focadas na realização de atividades fragmentadas, os corpos contidos das professoras e os corpos expandidos dos bebês desencontram-se, despotencializando as relações.
\end{abstract}

Palavras-chave: Narrativas corporais; Interações adultos e bebês; Creche.

\section{TO THINK ABOUT THE RITUALIZED ERASURE OF BODIES IN NURSERY: ADULTS, BABIES, ACTIVITIES}

\begin{abstract}
This text focuses on body narratives of teachers and babies in the spaces and times of a public day care center. Regarding the methodology, the data were generated through written and photographic records aiming to capture scenes of teachers and babies in interaction. In a second moment, meetings were held with the teachers to talk and analyze the visible scenes in the photographic records, raising other narratives. The results revealed that, in automated routines, focused on performing fragmented activities, the contained bodies of teachers and the expanded bodies of babies are mismatched, depotentializing relationships.
\end{abstract}

Keywords: Body narratives; Adult and baby interactions; Nursery.

\section{Introdução}

\begin{abstract}
A todo instante, o sujeito simboliza, por meio de seu corpo (seus gestuais, suas mímicas etc.), a tonalidade de sua relação com o mundo. Nesse sentido, o corpo, quaisquer que sejam as sociedades humanas, está sempre significativamente presente. Entretanto, as sociedades podem escolher colocá-lo à sombra ou à luz da sociabilidade (LE BRETON, 2012a, p.193).
\end{abstract}

\section{(i) (2)}

2019 Bonfim; Ostetto. Este é um artigo de acesso aberto distribuído sob os termos da Licença Creative Commons Atribuição Não Comercial-Compartilha Igual (CC BY-NC- 4.0), que permite uso, distribuição e reprodução para fins não comercias, com a citação dos autores e da fonte original e sob a mesma licença. 


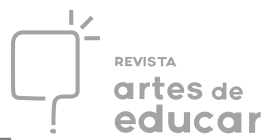

Desde a tenra idade, dizem os estudos, o corpo é presença viva e atuante nas relações com o mundo e nas interações com o Outro. Basta observar atentamente os gestos e movimentos de uma criança para decifrar o seu contentamento ao receber um presente, perceber o seu medo ao entrar no quarto escuro ou ainda, entender sua pressa de terminar uma tarefa para poder brincar.

Um possível risco para o qual Le Breton (2012a) nos alerta é de que este corpo vivo, expressivo e atuante como é o da criança, seja conduzido à sombra da sociabilidade. Em outras palavras, dependendo dos contextos culturais e sociais, das condições de atividades em que ele participa e, ainda, dos modos de interação a que ele é submetido, pode ocorrer um processo de apagamento ritualizado do corpo (LE BRETON, 2012a).

Considerando a potência de se estudar o corpo e a necessidade de se construir uma agenda de pesquisa que o considere como eixo central (LE BRETON, 2012b), este texto, fruto de uma pesquisa de doutorado ${ }^{3}$ em andamento, tem o propósito de discutir: que narrativas sobre/com o corpo são visíveis em um berçário considerando-se as interações entre adultos e bebês no cotidiano educativo?

Vale enfatizarmos que as interações são um dos eixos norteadores das práticas pedagógicas na Educação Infantil (BRASIL, 2010) e que é por meio especialmente do corpo que elas ocorrem no contexto de educação dos bebês, haja vista que nessa fase a linguagem verbal está em desenvolvimento. Sendo assim, os docentes dessa faixa etária assumem um papel primordial não apenas porque eles acompanham o processo de desenvolvimento e aprendizagem dos bebês, mas sobretudo, porque significam os gestos, o choro, as ações e as relações, qualificando-os ou desconsiderando-os.

O corpo neste trabalho é compreendido como o lugar e o tempo íntimo da condição humana (LE BRETON, 2012a) e, ao mesmo tempo, como a materialidade viva, que pensa, sente, age e interage (WALLON, 2007). Em diálogo com esses conceitos, na primeira parte do texto, discutimos como os movimentos e gestos do corpo são compreendidos a partir de sinalizadores culturais. Na segunda parte, apresentamos o percurso metodológico e os instrumentos de produção de dados de uma pesquisa que tem como lócus uma creche pública mineira. Na terceira parte, apresentamos e discutimos os dados de campo a partir do eixo de análise que surgiu com os próprios resultados, "em busca dos dizeres do corpo: relações, contensões e contradições". Por último, mas não menos importante, reflexões provisórias sobre a pesquisa em tela foram destacadas, deixando frestas para outras inquietações a serem 


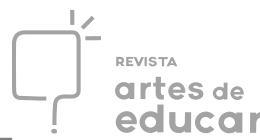

abordadas/discutidas no prosseguimento da análise dos dados e no aprofundamento da temática.

\section{Marcas culturais nos movimentos e gestos do corpo}

O corpo é uma temática que vem sendo discutida e apresentada, ainda que de forma incipiente, nos documentos que orientam as práticas pedagógicas de zero a três anos na creche (BRASIL, 2006, 2010, 2013; CAMPOS; ROSEMBERG, 2009). Nessas publicações, pudemos verificar que as explanações sobre o corpo estão relacionadas ao papel do movimento, aos hábitos e cuidados de higiene, à imagem corporal, à valorização e reconhecimento da diversidade étnico-racial, à aprendizagem e à formação da criança inteira.

Para nos auxiliar a definir o conceito de criança inteira recorremos aos estudos de Henri Wallon (1879-1962), um respeitável filósofo, médico e psicólogo francês, que propôs, em suas pesquisas no campo da psicogênese da pessoa completa, estudar as relações: atividade afetiva, motora e de inteligência da criança (WALLON, 2007).

Wallon (2007) trouxe contribuições significativas para a educação escolar ao abarcar elementos que possibilitam refletir que o desenvolvimento humano envolve muito mais do que as atividades cognitivas. Com isso, provocou resistências num contexto de convicções científicas marcadas pela memória e pela erudição herdada do positivismo.

A partir dos seus estudos, Wallon concluiu que não era possível reduzir as ciências do homem à neutralidade e objetividade como argumentavam alguns teóricos e cientistas de sua época. Foi esse um dos motivos que o fizeram optar por seguir na contramão dessa corrente de pensamento filosófico ocidental, o qual reforça a dualidade corpo-mente.

No percurso de buscar explicitar e dar coerência aos seus fundamentos epistemológicos e de análise, ele encontrou respaldo na concepção do materialismo históricodialético por compreender que, no homem, o social se amalgama ao orgânico. O ambiente humano infiltra o meio físico (WALLON, 2007, p. XLIV).

Como podemos observar, na proposta que Wallon denominou de psicologia dialética, os discursos em torno das dicotomias corpo-mente e biológico-social são superados. A partir desse entendimento, não é possível o corpo na escola ser reconhecido apenas como uma realidade biológica, mas ele precisa ser compreendido também como uma construção 


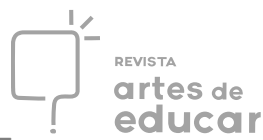

sociocultural, que influencia e recebe influências da sociedade, da cultura e das relações imbricadas nas interações com o Outro. Nesse aspecto, entendemos, de forma mais clara, como cada gesto pode variar, a depender do seu contexto cultural, como explica Le Breton (2009, p.59) citando Meo Zilio:

\begin{abstract}
"Assim, tocar a própria orelha significa, na Argentina, adulador, bajulador; no Uruguai, festejar um aniversário; no Paraguai, estar encarcerado; na América Central, indica a polícia; na Venezuela e alhures, uma ameaça de puxar a orelha das crianças; no Brasil, algo de belo, bem feito, bemacabado."
\end{abstract}

Se quisermos conhecer um pouco mais sobre as diferentes culturas, podemos retomar, também, o documentário Babies, uma das obras do cineasta francês Thomas Balmès (2010), que teve como objetivo registrar como se desenvolveram quatro bebês, no seu primeiro ano de vida: Bayarjargal, um menino, que morava no campo, em uma cabana na Mongólia, Ásia Oriental e Central; Ponijão, que vivia em uma tribo na Namíbia, África; Mari, uma menina, que residia em um alto prédio em Tóquio, no Japão; e Hattie, uma bebê, que morava numa casa em São Francisco, Estados Unidos da América.

Esse documentário levou-nos a perceber que a relação corpo e cultura precisa ser mais notada no que se refere à diversidade que à regularidade. Promoveu, também, a sensibilidade para refletirmos que a diversidade cultural e social está presente nas creches ainda que o contexto que pretendemos investigar seja o de crianças de uma mesma nacionalidade.

Não é hierarquizando as culturas que se trabalha a diversidade na escola, mas valorizando a riqueza que cada uma delas abarca e reconhecendo como cada uma, à sua maneira, imprime no corpo as marcas do humano. É por meio da cultura que os hábitos de higiene, liberdade ou repressão corporal vão ganhando sentidos e significados, e que a brincadeira, a arte, a música, a descoberta de si e o contato com o Outro e com o mundo se organizam.

O documentário leva à reflexão sobre o papel da motricidade nos processos de desenvolvimento da criança e reforça o que a perspectiva walloniana nos apresenta em sua teoria, conforme destaca Galvão (1995, p. 75): Cada cultura possui especificidades distintas no processo de objetivação e internalização do movimento. Esse processo pode ser sintetizado da seguinte forma: as dimensões do movimento estão estruturadas na função 


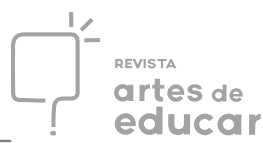

cinética, que ocorre com o corpo em deslocamento, como no caso de uma dança; e na função postural tônica, que se manifesta ainda que o corpo se encontre estático. Para exemplificar essa segunda função, podemos imaginar um bebê comprimindo seu tônus muscular ao ouvir uma história na creche que lhe causa medo. Ainda sobre esse tema, uma das questões que nos salta aos olhos nos diferentes contextos culturais apresentados por Balmès (2010) é a necessidade que o bebê tem de se movimentar e de experienciar o mundo por meio do brincar. Mas como o bebê se expressa corporalmente no contexto da cultura ${ }^{4}$ escolar?

Não apenas por meio da brincadeira, mas também de outras atividades expressivas, como a pintura ou a dança, por exemplo, o bebê cria diferentes estratégias para escapar ao controle do adulto e ressignificar o que lhe é apresentado. Nesse processo de criação de estratégias, destaca-se o papel fundamental do corpo como instrumento relacional com o mundo, possibilidade que Amorim e Rossetti-Ferreira (2008) chamam de corporeidade, manifestações corpóreas que conectam intimamente o sujeito ao contexto sociocultural. Dizem as autoras:

O corpo não representa uma instância individualizante, já que ele não existe primeiro e, depois, interage com o mundo externo. O mundo não existe 'lá fora', já que a pessoa é parte constitutiva do mundo. Ao contrário, a pessoa corporificada está intimamente conectada ao mundo, em um processo relacional, com o corpo representando a interligação eu-outro, a constituição da subjetividade sendo considerada de forma dependente do outro, da história e da cultura (AMORIM; ROSSETTI-FERREIRA, 2008, p. 78).

Tanto a leitura histórica quanto a cultural auxiliam a compreender a criança na vivência plena da sua corporeidade. Isso implica o entendimento de que o corpo é mais do que uma instância biológica; é uma unidade complexa, a qual tem como um dos seus pilares o movimento.

A motricidade da criança não é desvinculada dos seus pensamentos ou da sua afetividade, porém a temporalidade e os espaços das creches e pré-escolas, muitas vezes, reprimem os movimentos espontâneos. Em confronto com essa temporalidade institucional, o tempo da criança não é marcado pela fragmentação cronológica, mas reinventado a partir de cada experiência que ela vivencia consigo mesma, com os objetos e/ou com o Outro. Esse tempo abarca as brincadeiras, a música, a dança, a pintura e outras manifestações artísticas e expressivas, as quais podem permitir ao corpo se manifestar com maior leveza. 


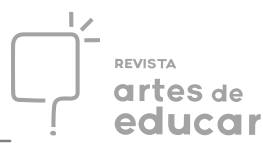

Um dos aspectos que pode contribuir para possibilitar a experiência do tempo aiônico, ou seja, o tempo próprio da criança na escola, é dar tempo para as reflexões sobre o corpo. Conforme Gatti e Barreto (2009, p. 58) verificaram, muitos cursos de Pedagogia não têm privilegiado nos currículos os conteúdos referentes à Educação Infantil ainda que a maior parte dos formandos esteja ingressando na carreira docente:

\begin{abstract}
Merece, ainda, atenção a enorme lacuna quanto à formação de professores para a educação infantil, uma vez que se trata do nível inicial da educação básica, que compreende vários anos de atenção à criança pequena e que concentra, como já se viu, o maior percentual de docentes sem formação adequada. Seguindo a tradição dos cursos de magistério de nível médio, os atuais cursos de Pedagogia costumam preparar concomitantemente o professor para atuar na educação infantil e no ensino fundamental. A suspeita é que, entendida, como em tempos passados, mais como uma complementação da formação do professor dos primeiros anos do ensino fundamental, a formação oferecida não esteja contemplando devidamente as especificidades da educação das crianças na pré-escola e nas creches.
\end{abstract}

Isso nos leva a refletir que se não houver investimento na formação inicial e continuada dos educadores, assim como em novas propostas de carreira e de incentivo à qualificação desses profissionais da Educação Infantil, continuará havendo uma grande lacuna na educação das crianças brasileiras de zero a cinco anos.

Consequentemente, o educador que não possui a devida formação estará mais vulnerável a adotar a reprodução e a trabalhar apenas com os seus próprios valores e/ou o estabelecido nos documentos institucionais. Estará propício, ainda, a disciplinar os corpos de maneira que estes não fujam ao controle do planejado e a criar espaços-tempos fragmentados e que acompanhem a lógica das nossas sociedades pós-industriais, nas quais o tempo é medido pelo rendimento que se obtém ao ocupá-lo (KOHAN, 2013).

O grande desafio é criar uma escola em que seja possível inverter a ordem, reaprender sobre e com as crianças e, acima de tudo, vivenciar o tempo aiônico, que abarca as experiências simultâneas do presente, do passado e do futuro sem dicotomizá-las, como Marques e Santos (2012) nos convidam a pensar. Uma escola na qual crianças e educadores contrariem a lógica de Cronos e busquem a emancipação humana. 


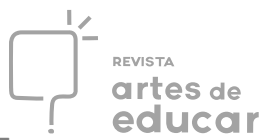

\section{Do referencial à metodologia: olhar, fotografar, dialogar e reconhecer as narrativas dos corpos}

A partir do enfoque dado à pesquisa - as interações corporais entre adultos e bebês no berçário -, iniciamos o processo de seleção da creche a ser investigada junto à Secretaria Municipal de Educação de Ipatinga, Minas Gerais. Dentre as opções de creches disponíveis, fizemos aproximação com uma delas - um dos Centros de Educação Infantil mais antigos da rede e de fácil acesso.

Em conversa com a equipe gestora da instituição, apresentamos as etapas do projeto. Buscamos, também, a autorização formal da Direção, das professoras do berçário e dos pais dos bebês. Para obtenção dessa autorização, conforme orientam Bogdan e Biklen (1994), apresentamos aos envolvidos a descrição e os objetivos do estudo, esclarecendo-lhes as dúvidas surgidas. Em seguida, começamos o período de observação no berçário, que durou cerca de três semanas no segundo semestre letivo de 2018.

Como pondera Chizotti (2006), toda observação atenta requer ferramentas apropriadas para o que se deseja focalizar. No nosso caso, em que o foco foram as interações corporais entre adultos e bebês, o diário de bordo e as fotografias se mostraram recursos fundamentais para a elaboração dos registros nesta etapa da pesquisa. Em relação ao primeiro, possibilitou associar os eventos com as manifestações dos corpos, contribuindo no sentido de auxiliar na interpretação dos dados, no que vinha antes e após as cenas capturadas pelas imagens. Conforme destaca Le Breton (2009, p. 53), o significado de um gesto ou de uma postura deduz-se no contexto preciso da interação.

Outro recurso primordial para a elaboração dos registros foram as fotografias, pois davam visibilidade às linguagens evidenciadas na relação corporal entre as professoras e os bebês no berçário por meio dos gestos, olhares, toques, acolhimentos, repulsas, aproximações, silêncios e outras sutilezas capturadas. As fotografias, também, foram potentes mediadoras/disparadoras das conversas que construímos com as professoras sobre os gestos e práticas do cotidiano em momentos posteriores às observações.

A ideia de como utilizar esse último recurso surgiu de um texto de Ostetto (2012), em que a autora dialoga tanto com questões decorrentes de sua experiência como docente do curso de Pedagogia, no campo da Educação Infantil, quanto com o material que vinha estudando à época de seu doutoramento sobre cultura, corpo e educação. 


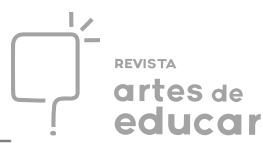

As imagens apresentadas no referido texto, de bebês e mulheres-educadoras em um berçário, indicaram um caminho, levando-nos a perceber a potência do registro fotográfico como recurso metodológico e como forma de reconstruir a memória e produzir linguagens comunicativas na elaboração dos dados. Na presente pesquisa, avançamos no sentido de mobilizar o olhar das professoras pelas imagens sequenciadas geradas durante o período de observação em campo. Essa mobilização ocorria durante os encontros com as professoras, em momentos previamente agendados e posteriores às observações, todos eles gravados em áudio e, em seguida, transcritos.

As imagens sequenciadas e projetadas via programa PowerPoint, no computador de uma das pesquisadoras, foram nossos dispositivos para abrir diálogos sobre o corpo com as professoras na creche. Nos limites do presente texto, as imagens que darão base às descrições apresentadas a seguir não serão aqui compartilhadas. Todavia, a descrição do observado é amplificada com o diálogo transcrito no encontro com duas das professoras em questão, tendo por mediação sequências fotográficas de suas interações com os bebês no cotidiano da creche.

\section{Em busca dos dizeres do corpo: relações, contenções e contradições}

O ser humano chega ao mundo com o corpo (LE BRETON, 2012b). E esse corpo, cada vez mais cedo, tem adentrado à escola, tem interagido com outros corpos em ambientes extrafamiliares e tem (re)significado práticas, mobilizado experiências e saberes, participado de encontros e desencontros.

O Episódio 1, a seguir, é o relato de uma atividade realizada na parte externa e anexa à sala dos bebês, observada e registrada no diário de bordo. Antes de contextualizá-la, é necessário esclarecer que, durante o período da pesquisa de campo, o berçário contava com quatro profissionais atuando junto aos bebês, sendo duas professoras regentes e duas professoras assistentes da Educação Infantil. Os bebês encontravam-se na faixa etária de 13 a 20 meses e eram ao todo 14 (dez meninos e quatro meninas).

$\mathrm{Na}$ referida atividade observada, uma das professoras conduzia os bebês em duplas para a realização de uma pintura para o Natal na parte externa da sala; claramente, organizava os preparativos para a data festiva do nosso calendário ocidental, socialmente comemorada por uns e desconsiderada por outros, e que tem assumido, cada vez mais, finalidades outras, 


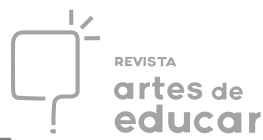

como a de cunho mercadológico. A proposta estabelecida pela docente era que cada bebê pegasse a esponja, que estava dentro de um recipiente com tinta, e a esfregasse no objeto a ser pintado. Larissa ${ }^{5}$, bebê de um ano e sete meses, foi repreendida por ela, porque cheirava a tinta, colocava-a na boca, esfregava-a na mesa e a experimentava com as mãos ao invés de manusear os objetos da forma estipulada.

Notamos que a criança buscou opções para vivenciar a atividade de corpo inteiro, não se limitando às orientações dadas pela professora, que insistia em padronizar os movimentos do corpo durante o processo. Larissa, no primeiro momento, apontou o dedo indicador direito para a professora; em seguida, movimentou a cabeça da esquerda para a direita várias vezes, como que querendo sinalizar que não estava satisfeita com aquele modo sugerido na atividade. Após esses movimentos, afastou o objeto a ser pintado e continuou marcando a mesa com suas mãos molhadas de tinta; olhou para a câmera e sorriu ao perceber que estava sendo fotografada. Com olhares, gestos e movimentos corporais, Larissa desafiou o corpo do adulto e contradisse o planejado. No entanto, a professora não percebeu a linguagem da bebê durante a interação. Com isso, [...] parece que o corpo apaga-se, que ele desaparece do campo da consciência, diluído no quase automatismo dos ritos diários (LE BRETON, 2012b, p. 192).

A narrativa da professora, diante da sequência de fotos sobre o Episódio 1, projetada no encontro que realizamos para conversar sobre as imagens capturadas, foi a seguinte:

Essa foi a atividade de pintura deles. É a atividade, acho que foi pra... de Natal para poder enfeitar aqui o lado externo da creche com os Papais Noel. E eu acho interessante o trabalho aqui da creche é isso, que são eles mesmos que fazem, assim, o trabalho. Não é a gente que pega, que pinta tudo. Eles que estão ali usando a mãozinha, usando a tinta. Tudo o que tem à disposição aqui fora tem a mãozinha deles. Tem a mãozinha de todos. E aqui é a Larissa, não é? Adora fazer essa atividade de pintura. É uma das paixões dela. São essas atividades. E a Lídia... De início, a Lídia não gostava muito de mexer com tinta. Ela tinha um receio. A questão da tinta. Ela não gostava, assim, de sujar a mão, de melecar, mas depois eu pude observar que ela começou a se adaptar melhor, gostar mais de fazer esse tipo de atividade. Quando eu cheguei, ela não gostava muito de se sujar, de mexer com tinta. A Larissa sempre gostou [risos]. Alguns bebês tentaram fazer outra coisa, porque essa atividade era pra pintar com a esponja, mas tinham uns que usavam as mãos. Aí, começavam a lambuzar ali na mesa, tudo. Aí, até a questão de escolher por duplas é melhor. É mais fácil estar trabalhando com eles de dois a dois do que levar mais alunos e dar muita bagunça (REGISTRO DO ENCONTRO EM 04/12/2018. Narrativas da professora Hosana sobre o Episódio 1). 
A professora demonstrou um desconforto em relação ao fato de a criança não realizar a atividade conforme o planejado, pois o objetivo era específico: pintura, com esponja; mas alguns bebês fizeram outra coisa, usaram as mãos, lambuzaram a si e a outros objetos, avaliou a professora. O que não estava previsto foi desqualificado, porque o central não era a criança, seus interesses, seus movimentos, suas expressões, suas experiências, mas a pobre e desinteressante atividade. Assim, a criança vai sendo deixada à sombra e seu corpo apagado pelo automatismo impresso na ação docente, que é guiada pelo "ter que fazer", porque é Natal, porque tem que enfeitar a creche, porque...

Queríamos ver os corpos em relação. Mas tinha uma data comemorativa no meio do caminho. Por quê? Eis um aspecto que poderia se desdobrar em foco de análise. Nos limites do presente artigo, optamos por não aprofundar os determinantes e as implicações de práticas pedagógicas pautadas em datas comemorativas e em realização de atividades fragmentadas e, de certa maneira, impróprias, haja vista que desconsideram as especificidades dos bebês. Para o que nos interessa - os gestos, os corpos, as relações -, consideramos que basta apontar que tais concepções e práticas impõem limites aos corpos e empobrecem as experiências, como ficou explícito na descrição da cena observada.

Voltando ao foco, podemos perceber que a postura corporal da professora, especificamente nesta atividade, deu pouco ou nenhum espaço para a experiência da criança, demonstrando maior ênfase ao produto do que ao processo. Ainda que tenha comentado: “Tudo o que tem à disposição aqui fora tem a mãozinha deles. Tem a mãozinha de todos", fazendo referência aos enfeites que estão no pátio e nos corredores da creche. Eram evidentes a falta de autonomia e autoria das crianças, o controle e a contenção.

Nesse episódio, pudemos verificar que a atividade, tomada como um direcionamento da professora para a criança executar (no caso específico, de preparativos para o Natal), acabaram gerando um tensionamento corporal da docente devido à necessidade da produção de um número significativo de enfeites em um curto espaço de tempo. Afinal, eram 14 crianças muito pequenas! Não havia tempo-espaço para descontrair o corpo, interagir de forma mais espontânea e alegre, trocar experiências e saberes, ouvir e ser ouvido, acolher. Estava configurada a postura clássica do professor tradicional, que dá a tarefa (a atividade) e espera que seja realizada, pelo aluno, a contento, passivamente. 


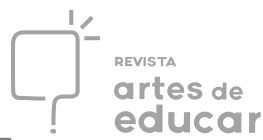

Considerando que a docência, nessa mesma turma de bebês, é compartilhada, verificamos, ainda, resultados semelhantes em um episódio com outra professora, que aqui denominaremos de Episódio 2 e que também envolve os preparativos para uma outra festa na creche.

Segundo os relatos descritos no diário de bordo, as professoras estavam tensas, porque a equipe gestora tinha solicitado a elas que cada turma deveria preparar uma apresentação para o dia da festa "Mostra Viva". Ficou definido que a sala dos bebês iria realizar uma coreografia. Para que eles entendessem qual o posicionamento do corpo na ocupação do espaço, Iolanda, a outra professora regente da turma, colocou vários pneus na sala e, dentro deles, a foto de cada bebê. A intenção, como percebemos nos diálogos da professora com os bebês, era que eles identificassem suas fotos e permanecessem delimitados em um espaço específico; ou seja, um bebê dentro de cada pneu, cantando e imitando os gestos e movimentos coreográficos da professora.

Nesse dia do ensaio, os bebês estavam atentos aos movimentos rápidos da docente. Seus olhares de curiosidade a acompanhavam no andar pela sala, ao procurar selecionar as fotos, ao separar a fita adesiva e ao abaixar-se para afixar as imagens dentro de cada pneu. Alguns se aproximaram dela, enquanto outros brincaram com os demais pneus tentando empurrá-los; assim, expressavam corporalmente o peso daqueles objetos. A professora se abaixou. Nesse momento, Bruna, uma bebê de um ano e quatro meses, que estava distante, se aproximou. Elias, também da mesma idade, sentou-se no chão, fez movimentos com a cabeça e os pés, observou a fita adesiva e tentou pegá-la; em seguida, colocou a mão esquerda na foto que a professora estava colando no chão. Durante esse processo, Iolanda iniciou um diálogo com eles: “- De quem é essa foto?” Dois deles apontaram com os dedinhos para a colega. A professora não percebeu a resposta, porque estava de cabeça baixa, mas continuou: “- Esse coleguinha é uma menina ou um menino?" Iana, uma bebê de um ano e oito meses, que também compunha a cena, olhou para a professora e pegou em seu próprio cabelo, como que querendo dizer que era uma menina como ela. Entretanto, a professora pareceu continuar achando que não estava obtendo as repostas no diálogo: “- Qual a cor da roupa dela?” Patrick, de um ano e dois meses, caminhou até o móbile, que estava próximo, balançou-o e colocou o dedo na fita amarela. Nesse momento, a professora levantou a cabeça, observou o movimento do bebê e disse: “- Parabéns, Patrick! Na roupa dela também tem amarelo!” Após essa fala da professora, o menino sorriu. 


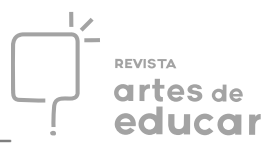

As palavras de Pereira (2018, p. 29) iluminam a busca de significados implicados na cena observada e dão pistas para a interpretação do ocorrido:

Gestos e movimentos infantis são muito mais que uma forma de a criança acessar objetos ou de se deslocar no espaço, são maneiras de perceber o que a cerca e de se expressar, refletem sensações, emoções e pensamentos. É através do corpo que a criança responde aos estímulos que recebe a cada momento, que entra em contato com seu meio ambiente, com as pessoas, enfim, com o mundo que ela está descobrindo e conhecendo. Ela não 'vê' apenas com os olhos, 'vê' com o corpo inteiro, ela precisa pegar um objeto, sentir a textura, se é leve ou pesado, se faz barulho ou se não faz nada, analisar suas possibilidades, descobrir seus mistérios.

O cenário preparado pela professora, com os pneus, as fotos e a música, poderia ter constituído um rico ambiente de interação e exploração para os bebês. Quer dizer, fora do planejado pela professora, as crianças (con)viviam com as possibilidades dos materiais, explorando-os, conforme relatado: brincavam com os pneus que não estavam sob o controle/arrumação da professora para a atividade coreográfica, tentavam empurrá-los, faziam força com o corpo, experimentavam o peso daqueles objetos. As tentativas de pegar a fita adesiva, sentando, levantando, acionando pés e mãos, o corpo inteiro, expressavam toda a sua vivacidade corporalmente. Entretanto, o foco na pretensa atividade e as formas docentes de interpelar didaticamente as crianças (nota-se nas perguntas pouco interesse genuíno e visíveis situações de ensino) não deixavam espaço para ouvi-las em suas múltiplas linguagens, provocadas na relação com o ambiente.

Como escreveu Pereira (2018), as crianças não veem apenas com os olhos, mas com o corpo inteiro. Nesse modo de ver intenso/inteiro, vão desenhando gestos nos espaços, nos encontros, no movimento. Quando o professor está preocupado com a atividade, seja direcionada pelas datas comemorativas, ou não, em regra, sua performance corporal desconsidera os modos de ver de corpo inteiro, que são maneiras de conhecer a criança, de ser e de estar no mundo singulares. O foco na atividade produz jeitos de corpos pouco acolhedores aos gestos, que são linguagens e, portanto, os professores acabam por não as escutar.

Até esse momento da realização da proposta, a professora, embora agitada, demonstrava-se satisfeita. Entretanto, no momento seguinte, especificamente no ensaio da 
festividade, o sentimento laborioso em relação à tarefa ganhou destaque. Esse fato foi enfatizado em sua narrativa durante o encontro que realizamos:

[Professora]: Nessa cena, eu estava pregando as fotos para o ensaio da apresentação da 'Mostra Viva'. Aí, cada criança teria que identificar sua foto e entrar dentro do pneu. Mas não deu muito certo no dia, sabe? Porque cada um queria entrar no pneu do outro. Eles conheciam, eles sabiam identificar, mas não queriam seu pneu. Queriam o do colega [risos]. Então, não deu muito certo. E quando um entrava no pneu do colega e o colega via, começavam a brigar, porque ele queria ficar no pneu dele. Por isso, no dia da apresentação, deixamos sem a foto. E como estava chovendo também nesse dia, o espaço foi reduzido. Foi tudo no refeitório onde ficam as mesas. Então, não daria. Porque a proposta era: chamar eles, um por um, pra cada um entrar dentro do pneu. Mas o pátio estava todo encharcado de água. Então, não dava pra fazer desse jeito. Porque esse era o objetivo. Aí, nós tivemos que levar os bebês, carregá-los, porque tinha o perigo de cair, né? Porque estava molhado o chão. Mas, aí, nós estávamos ensaiando a música Tico-tico, porque estava relacionada também com o livro que era o nome da nossa turma. Passarinho Branco, né? Aí, era uma música que tinha a ver com o nome da turma. Nós confeccionamos, fizemos o ninho. O pneu era pra ser o ninho. Foi o ninho e a gente colocou palhas do lado de fora, do lado de dentro. Foi uma apresentação muito bonita. Pra ensaiar com eles no decorrer da semana, era trabalhoso. Eles não ficavam dentro do pneu. A música passava, você cantava, você gesticulava e eles não faziam. Eram uns dois que faziam, que ficavam dentro do pneu, mas no dia foi perfeito. A gente acha, às vezes, que eles não estão observando, que eles não estão nem aí para o que a gente está fazendo lá na frente, mas no dia eles fazem. Então, tipo assim, a gente cantava com eles umas três vezes, pra não ficar cansativo para eles e nem para nós. Quando chegou no dia, perfeito: bateram palma, gesticularam, foi lindo! E na sala, eles não faziam. Eram poucos que faziam. Eles observam. Eles veem, sim, o que a gente está fazendo, mas não fazem na hora que a gente quer [risos].

[Pesquisadora]: Você se lembra da letra da música?

[Professora]: 'Lá naquele ninho, um, dois, três. Havia três ovinhos. Um, dois, três. Daqueles três ovinhos, um, dois, três. Nasceram Tico-ticos, um, dois, três'. Aí, repete a música. Como é contagem oral, a gente buscava, junto com a música, socializar, casar com as atividades da sala: 'um, dois, três', mostrando os dedinhos. O gesto do passarinho. Bater palma. Aí, eles fizeram no dia. Os pequetitinhos ainda não dão conta de mexer com os dedinhos, levantar um por um. Aí, ficavam balançando os dedinhos. Batiam palma. Alguns faziam movimento com as mãos como se estivessem batendo as asas. Ficou lindo! (REGISTRO DO ENCONTRO EM 28/11/2018. Narrativas da professora Iolanda sobre o Episódio 2).

Como enfatiza Wallon (1975), uma das principais atividades nesse período em que os bebês se encontram é a atividade motora. É por meio dela que os bebês manifestam seus desejos, correm, abaixam-se, levantam-se, pegam os objetos, afastam-se e se aproximam das Revista Interinstitucional Artes de Educar. Rio de Janeiro, V. 5, N.3- pág. 491-507 set-dez de 2019: "Educação: Corpo em movimento." - DOI: 10.12957/riae.2019.45278 


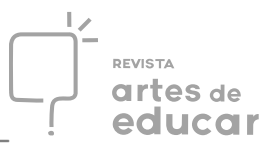

pessoas. Aprofundando esse enfoque na sua teoria, fica mais claro compreendermos o Episódio 2 não como uma falta de ordem no ensaio, mas como uma necessidade por parte da criança de aprender se movimentando.

Considerando-se a complexidade do trabalho pedagógico na Educação Infantil e, mais ainda, com grupos de bebês, no processo da pesquisa, buscamos também perceber e acolher a diversidade de fazeres e saberes docentes. Assim é essencial frisar que, em outros momentos de interação observados, diferentes posturas das duas professoras foram identificadas. Com mais abertura e flexibilidade em relação aos bebês, as professoras em questão mostraram-se mais próximas do grupo, interagindo com mais liberdade em relações acolhedoras. Mas esses são episódios e histórias a serem contados e problematizados na continuidade das análises.

\section{Para continuar...}

O rapaz chegou-se para junto da moça e disse: - Antônia, ainda não me acostumei com o seu corpo, com a sua cara./ A moça olhou de lado e esperou./ - Você não sabe quando a gente é criança e de repente vê uma lagarta listada?/ A moça se lembrava: - A gente fica olhando... A meninice brincou de novo nos olhos dela./ O rapaz prosseguiu com muita doçura: Antônia, você parece uma lagarta listada./ A moça arregalou os olhos, fez exclamações./ O rapaz concluiu: - Antônia, você é engraçada! Você parece louca. (QUEIRÓS, 2013. Poema Namorados, de Manuel Bandeira)

$\mathrm{Na}$ pesquisa, os corpos nos fascinam assim como as tonalidades, os movimentos inesperados e a vivacidade de uma lagarta listada encanta a uma criança. Por isso, "A gente fica olhando...”: as imagens dos corpos nas fotografias, o olhar das professoras sobre seus próprios corpos e os dos bebês.

No contexto dos dados aqui apresentados, foi possível verificarmos que, por um lado, o corpo da criança é em alguns momentos tolhido, desconsiderado, por outro, o corpo do professor, devido à aceleração das atividades em um curto período de tempo, é levado a não perceber a si mesmo e a riqueza dos processos e das experiências infantis. Isso é fruto de uma rotina imposta, que desconsidera as especificidades dos bebês e é sustentada pela realização das chamadas "atividades". Quando o planejamento pedagógico foca a atividade, o produzir, o fazer direcionado pelo professor, a criança desaparece da cena (OSTETTO, 2000). Na tensa relação produção e produto, o produtor é negligenciado, suas necessidades e seus desejos são Revista Interinstitucional Artes de Educar. Rio de Janeiro, V. 5, N.3-pág. 491-507 set-dez de 2019: "Educação: Corpo em movimento." - DOI: 10.12957/riae.2019.45278 


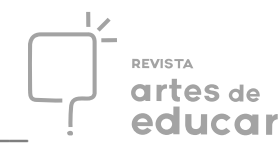

facilmente desconsiderados. A atividade, pretensamente pedagógica, ofusca a genuína ação da criança, compreendida como experiência no/com o mundo. Para utilizarmos a expressão empregada por Le Breton (2012a), o corpo é apagado, não é visto, é secundarizado. E a criança, como todo ser humano, não tem um corpo: é o corpo!

Este foco na atividade, que produz o apagamento ritualizado dos corpos, de que estamos falando, pode ser percebido mais claramente em períodos que antecedem as festividades e datas comemorativas do que em outros analisados até o momento. Nesses períodos, há uma exigência explícita da equipe gestora e/ou da família dos bebês por pinturas e ensaios musicais, teatrais e coreográficos, que menos possibilitam o olhar atento para o corpo e mais contribuem para os automatismos nas relações e interações entre adultos-bebês. Consequentemente, há um enrijecimento visível do corpo das professoras nessas práticas, assunto este que pretendemos aprofundar no decorrer da pesquisa.

Afora a necessidade de se problematizarem tais práticas, pois reduzem a autonomia das crianças e a possibilidade de criação (OSTETTO, 2016), sinalizam a importância de, ainda, colocarem-se em pauta as relações e os conteúdos, que (in)formam as práticas docentes e, em suas restrições, (en)formam os corpos infantis. Em última análise, observamos que a rotina da creche, em alguma medida e em certas atividades, restringe a polissemia do corpo.

\section{REFERÊNCIAS}

AMORIM, K. S.; ROSSETTI-FERREIRA, M. C. Corporeidade, significação e o primeiro ano de vida. Arquivos Brasileiros de Psicologia, v. 60, p. 67-81, 2008.

BALMÈS, T. Babies. 2010. Disponível em: <https://vimeo.com/67691334>. Acesso em: 10 abr. 2019.

BOGDAN, R. C.; BIKLEN, S. K. Investigação qualitativa em educação: uma introdução à teoria e aos métodos. Tradução Maria João Alvarez e Telmo Mourinho Baptista. Revisão António Branco Vasco. Portugal: Porto Editora, 1994.

BRASIL. Ministério da Educação. Parâmetros Nacionais de Qualidade para a Educação Infantil. Brasília: MEC/SEB/DICEI, 2006. v. 1.

BRASIL. Ministério da Educação. Secretaria de Educação Básica. Diretrizes Curriculares Nacionais para a Educação Infantil. Brasília: MEC/SEB, 2010. 


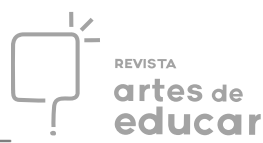

BRASIL. Ministério da Educação. Secretaria de Educação Básica. Diretrizes Curriculares Nacionais para a Educação Básica. Brasília: MEC/SEB, 2013.

CAMPOS, M. M.; ROSEMBERG, F. Critérios para um atendimento em creches que respeite os direitos fundamentais das crianças. 6. ed. Brasília: MEC/SEB, 2009.

CHIZOTTI, A. Pesquisa qualitativa em ciências humanas e sociais. Petrópolis, RJ: Vozes, 2006.

GALVÃO, I. Henri Wallon: uma concepção dialética do desenvolvimento infantil. Petrópolis, RJ: Vozes, 1995.

GATTI, B. A.; BARRETTO, E. S. de S. Professores do Brasil: impasses e desafios. Brasília: Unesco, 2009.

KISHIMOTO, T. M. Educação Infantil no Brasil e no Japão: acelerar o ensino ou preservar o brincar? Revista Brasileira de Estudos Pedagógicos, Brasília, v. 90, n. 225, p. 449-467, maio/ago. 2009.

KOHAN, W. O. O mestre inventor. Relatos de um viajante educador. Tradução Hélia Freitas. Belo Horizonte: Autêntica, 2013.

LE BRETON, D. As paixões ordinárias: antropologia das emoções. Tradução Luís Alberto Salton Peretti. Petrópolis, RJ: Vozes, 2009.

LE BRETON, D. Antropologia do corpo e modernidade. Tradução Fábio dos Santos Creder Lopes. 2. ed. Petrópolis, RJ: Vozes, 2012a.

LE BRETON, D. A sociologia do corpo. Tradução Sonia Fuhrmann. 6. ed. Petrópolis, RJ: Vozes, $2012 b$.

MARQUES, L. P.; SANTOS, N. A. S. No rastro dos tempos e das infâncias: conversas que (des)conversam no interior da escola. In: MARQUES, L. P.; MONTEIRO, S. da S.; OLIVEIRA, C. E. de A. (Org.). Tempos: Movimentos Experienciados. Juiz de Fora: Ed. da UFJF, 2012. p. 199-218.

OSTETTO, L. E. Planejamento na educação infantil: mais que a atividade, a criança em foco. In: OSTETTO, L. E. (Org.). Encontros e encantamentos na educação infantil. Campinas, SP: Papirus, 2000. p. 175-200.

OSTETTO, L. E. Dos gestos na Educação Infantil: textos no corpo. In: OSTETTO, L. E.; LEITE, M. I. Arte, Infância e formação de professores. 7. ed. Campinas: Papirus, 2012. p. $121-128$

OSTETTO, L. E. Formação de consumidores ou criadores? Cultura e arte na educação infantil. In: REIS, M.; BORGES, R. (Org.). Educação infantil: arte, cultura e sociedade. Curitiba: CRV, 2016. p. 315-336. 


\section{PEREIRA, L. H. P. O que eu gostaria de já saber com filhos e alunos pequenos: um olhar} para a educação infantil. Curitiba: CRV, 2018.

QUEIRÓS, B. C. de. Para querer bem. Antologia poética de Manuel Bandeira. 2. ed. São Paulo: Global, 2013.

WALLON, H. Psicologia e educação da infância. Lisboa: Editora Estampa, Ltda., Lisboa para a Língua Portuguesa, 1975.

WALLON, H. A evolução psicológica da criança. Tradução Claudia Berliner. Revisão técnica Izabel Galvão. São Paulo: Martins Fontes, 2007.

\footnotetext{
${ }^{\text {i }}$ Doutoranda em Educação pela Universidade Federal Fluminense. Mestre e Pedagoga pela Universidade Federal de São João del-Rei. Membro do grupo de pesquisa FIAR - Círculo de estudo e pesquisa Formação de professores, Infância e Arte. Pedagoga no IF SUDESTE MG - campus Muriaé/MG/Brasil. E-mail: patricia.ftbp@gmail.com Orcid: 0000-0002-6989-7034.

ii Professora da Universidade Federal Fluminense, Niterói/RJ/Brasil, onde atua no Curso de Pedagogia e no Programa de Pós-graduação em Educação. Coordenadora do grupo de pesquisa FIAR - Círculo de estudo e pesquisa Formação de professores, Infância e Arte. Pedagoga pela UFSC, Mestre em Educação pela UFSCar e Doutora em Educação pela UNICAMP. Contemplada pelo Programa Professor Visitante no Exterior - CAPES 2018/2019, desenvolveu a pesquisa A formação estética e cultural de professores para a educação infantil: Brasil e Portugal em diálogo, na Universidade de Évora/Portugal.

E-mail: lucianaostetto@id.uff.br Orcid: 0000-0002-1948-5090.

${ }^{3}$ A pesquisa contou com recursos financeiros do Programa de Apoio à Qualificação de Servidores do IF Sudeste MG (PROAQ/Muriaé).

${ }^{4}$ Segundo Kishimoto (2009), citando Mouritzen, cultura é algo peculiar, relativo às atividades humanas, produções, formas de expressão, comportamentos e instituições sociais gerados, processados e formatados por um tempo particular.

${ }^{5}$ No intuito de resguardar a identidade das professoras e a dos bebês que fizeram parte da pesquisa, optamos por utilizar pseudônimos.
} 